\title{
Higher training in old age psychiatry: a survey of senior registrars' experiences
}

\author{
Barbara Beats, Senior Registrar, Maidstone Hospital, Maidstone ME16 9QQ; \\ GeraRD BAGLEY, Senior Registrar, Knowle Hospital, Fareham PO17 5NA; VICTORIA \\ Banks, Senior Registrar, Barrow Hospital, Bristol BS19 3SG; PATRICIA Cronin, \\ Senior Registrar, St Nicholas Hospital, Newcastle Upon Tyne NE3 3XT; and \\ GOEDELE OPDEBEECK, Senior Registrar, Queen's Park Hospital, Blackburn BB2 3HH
}

If high quality services are to be provided for the elderly mentally ill throughout the country it is now recognised that specialist teams are needed, led by adequately trained old age psychiatrists (Wattis et al, 1981).

Prompted by the example set by the British Geriatric Society (Forsyth, 1992) a working party was set up to devise a postal questionnaire to investigate trainees' experiences of senior registrar (SR) training in old age psychiatry.

\section{The study}

In October 1989, 65 senior registrars training in old age psychiatry in 17 regions of England and Wales were identified from the Royal College of Psychiatrists Section of Old Age Psychiatry membership list. A postal questionnaire (available from Dr Beats or from Jean Wales at the College) was sent to each individual to be completed anonymously. The questionnaire covered career aims, general aspects of training and pastoral care as well as details of old age and general training posts, geriatric medical experience, management experience and research. Free comments were also solicited. The initial mailshot included a postcard to be returned separately from the completed questionnaire; thus after one month defaulters were sent a reminding letter and second questionnaire.

\section{Findings \\ People and posts}

Fifty-two (80\%) responses were received from SRs in $16(94 \%)$ regions; $87 \%$ planned to become specialist old age psychiatrists and $6 \%$ general psychiatrists with an interest in the elderly mentally ill; the rest were undecided. Over half were currently working as SRs with old age trainers, one third with general psychiatry trainers, the remainder being either research workers or lecturers. Only one respondent was training part-time, and although the majority
(70\%) were aware of opportunities for such training, comments were made that such posts were "difficult to arrange" or even "not regarded as good training posts".

\section{Clinical experience}

The Figure illustrates the training opportunities available to respondents in a variety of clinical areas. Data from respondents currently working in the psychiatry of old age are shown; those working in general psychiatry posts made broadly similar observations. Although there was great variation across the country, most areas of hospital based experience were well covered, e.g. in-patient and out-patient care, work within the multidisciplinary team, liaison with geriatricians, and teaching medical students and other professionals. However, work with external agencies such as social services, general practitioners and the voluntary sector was less common.

\section{Supervision and guidance}

Seventy per cent of senior registrars received regular formal supervision from their consultants, $30 \%$ did not. Only $\mathbf{4 0} \%$ were able to see and discuss a written review of their performance in a given post, another $40 \%$ were unaware of the occurrence of any formal assessment or review. Career guidance also appeared to be rather patchy. Only five $(10 \%)$ respondents had an independent person designated to give advice, although $65 \%$ felt this would be useful. The College requires trainees in each region to meet regularly with tutors in old age and general psychiatry during their higher training. Twenty respondents $(39 \%)$ claimed to have both a general and an old age psychiatry tutor but only seven $(14 \%)$ met both regularly. However, of 13 respondents who had an old age tutor alone, the majority (10) met their tutor regularly.

\section{Research}

The majority of respondents $(78 \%)$ were able to spend at least two sessions per week actively pursuing 


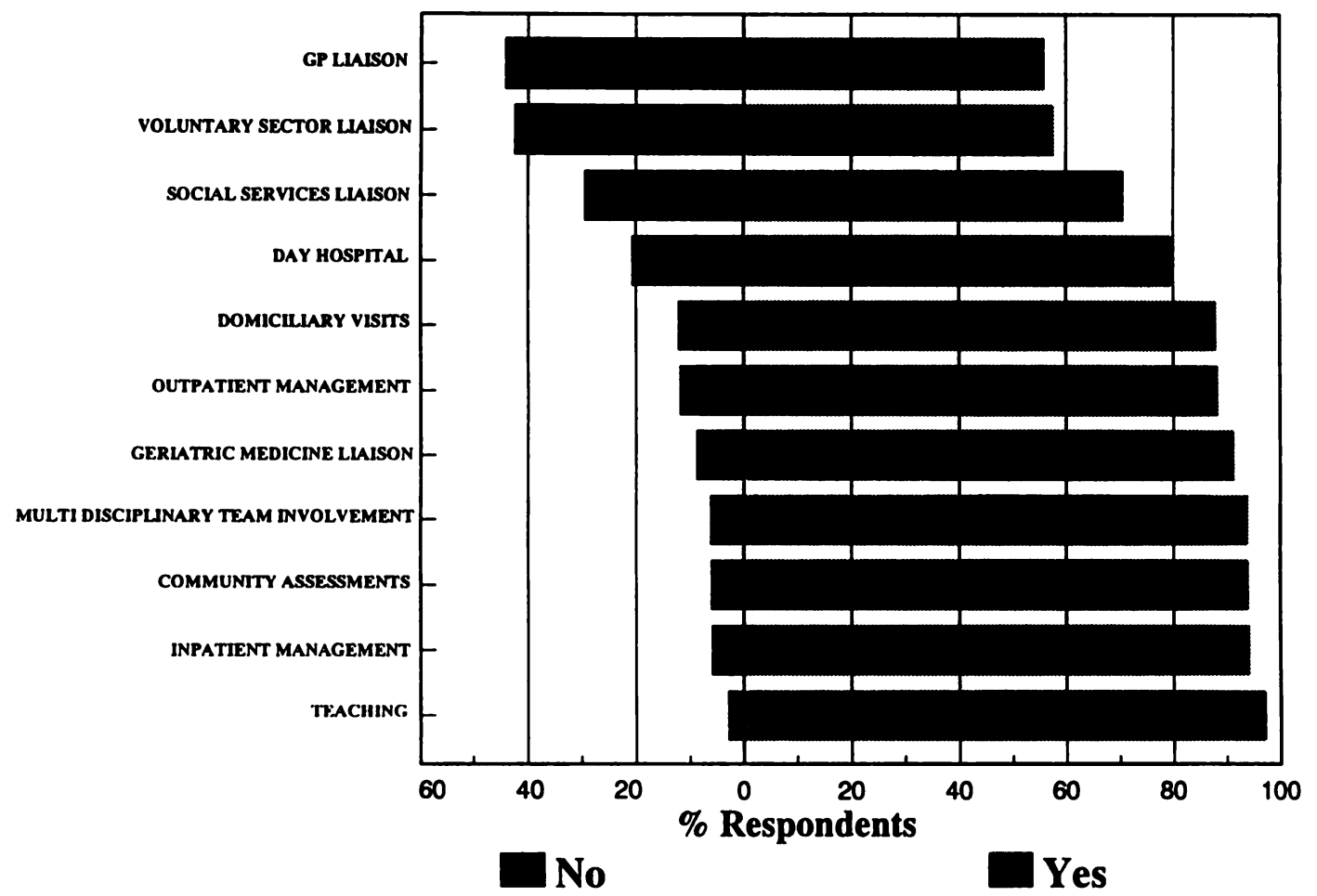

Fig. 1 Clinical experience available in senior registrar posts in old age psychiatry.

research interests but two (4\%) had no time available for research because of service commitments. However, although an overwhelming $96 \%$ felt that research was encouraged by their trainers only 17 $(33 \%)$ were getting regular supervision for their projects.

\section{Management experience}

Thirty-six SRs $(70 \%)$ had attended a management course and $45(87 \%)$ claimed to have had practical experience of management, ranging from spending time "shadowing" district or unit managers to attending committee meetings intended to plan future services or simply being responsible for drawing up the "on-call" rota; $54 \%$ had taken part in medical audit.

\section{Geriatric medical experience}

All respondents said they were expecting to spend time as a consultant liaising with geriatricians. Forty-three felt it was important to gain experience of geriatric medicine during their higher training. The availability and arrangements for such training were widely variable. Of SRs currently working with old age trainers, $23(77 \%)$ were receiving training in geriatric medicine. Of those attached to general psychiatrists only four were able to spend time training in geriatric medicine. Most SRs were training on a sessional basis; only eight $(30 \%)$ had spent a fulltime attachment of six weeks or more. Only $23 \%$ of respondents had access to regular academic meetings with local physicians. Seventeen SRs intent on a career in old age psychiatry had worked in geriatric medicine at SHO level; two had been registrars and one a consultant. Four respondents had either MRCP or MRCGP and one had recently obtained the Diploma in Geriatric Medicine.

\section{Comments}

Most regions were represented in the survey, although often by only one or two trainees. It was the clear impression of the working party that considerable variation exists from region to region both in the number of training posts available and the clinical content of the posts.

It is noteworthy that an overwhelming majority $(87 \%)$ of senior registrars planning careers in old age psychiatry wish to be pure old age psychiatrists and to gain adequate training by undertaking more than one old age placement. Many feel "under pressure to take up consultant posts before full training". Parttime trainees were under-represented and we were 
surprised and perturbed by the negative attitudes expressed to part-time training. The difficulties experienced by those wishing to work part-time ranged from ignorance about available schemes such as the PM79(3), to long delays in securing funding once manpower approval was gained. Vigilance is required to improve this situation.

Trainees clearly value regular clinical supervision from their current 'firm' consultant but at the time of the survey $30 \%$ were not getting any supervision. Aside from considerations of the likely quality of training in unsupervised posts, it is also of concern that those with no experience of receiving adequate supervision will find this responsibility to junior staff more difficult to discharge once they become consultants themselves. The recently established tutors in old age psychiatry were also much appreciated. However 19 of those respondents currently working in general psychiatry posts had no tutor in old age psychiatry, despite expressing an interest in a career in the specialty.

The traditional clinical areas seem to be well covered in training posts but areas such as liaison with general practitioners, the voluntary sector and social services often were not. Since experience in such areas will be of increasing importance for future consultants as mental health services move from hospital to community, trainees should be encouraged to explore them (Murphy, 1991).

Some training in geriatric medicine is available to most trainees, usually during 'old age' attachments. There is considerable variation in arrangements. Flexibility should be maintained but it seems likely that many trainees would benefit from receiving more formal training in geriatric medicine and from greater exposure to joint academic endeavour.

The College has placed great emphasis on the importance of trainees gaining research experience. Indeed almost all SRs responding to this survey have time available for research. Unfortunately adequate supervision seems less readily available. It seems likely that poorly directed research time will not be spent in pursuing potentially fruitful projects and may account for a degree of cynicism about research expressed by a number of respondents.
Most trainees are taking up the challenge of management involvement and had in some cases gone to great lengths to design their own management training including organising management courses and exploring the processes of both district and regional finance and planning. Indeed one trainee has become so interested in the process of NHS management he plans to study for an MBA.

\section{Conclusion}

Overall this study shows that this group of trainees, in common with many others, values a varied clinical training programme with close contact with and supervision from trainers (Fahy \& Beats, 1990). Senior registrars value their supernumerary status, which is essential if training is to remain flexible and allow those coming into a post from a variety of backgrounds to make the best use of the training offered. The major problems that have been highlighted are those of a lack of community involvement in some services, some difficulties with and ambivalence about part-time training and a lack of supervision for research.

\section{References}

Fahy, T. \& Beats, B. C. (1990) Psychiatric training at the Maudsley Hospital: a survey of junior psychiatrists experiences. Psychiatric Bulletin, 14, 289-292.

ForsYTH, D. (1992) Psychogeriatric training for senior registrars in geriatric medicine. Psychiatric Bulletin, 16, 78-79.

MURPHY, E. (1991) Report of the working group on the training implications of the move towards community orientated treatment (letter) Psychiatric Bulletin, 15, 367.

Wattis, J. P., Wattis, L. \& Arie, T. (1981) Psychogeriatrics-a national survey of a new branch of psychiatry. British Medical Journal, 282, 1529-1533.

\& JOLLEY, D. J. (1989) Survey into the availability of higher specialist training in the psychiatry of old age in England and Wales 1983-1988 and yield of consultants from the training schemes. Psychiatric Bulletin, 13, 514-524. 